\title{
Impacto da doação de sangue nos depósitos de ferro do organismo de doadores
}

\section{Impact of blood donation on donor iron reserves}

\author{
Rita C. Mousinho-Ribeiro ${ }^{1}$ \\ Gabriella P. Sousa ${ }^{1}$ \\ Thiago M. Nunes ${ }^{2}$ \\ Marcelo C. Neves ${ }^{2}$
}

${ }^{1}$ Professora de Hematologia do Instituto de Ciências Biológicas, Universidade Federal do Pará, Belém, Brasil.

${ }^{2}$ Farmacêutico-Bioquímico, Especialista em Análises Clínicas pelo Centro Universitário do Pará, Belém, Brasil.

\section{Sr. Editor}

O ferro é um elemento absolutamente essencial à maioria dos processos fisiológicos do organismo, desempenhando função central no metabolismo energético celular e atuando de modo decisivo na eritropoese. ${ }^{1}$ Em adultos normais, a quantidade de ferro absorvida, diariamente, equivale à quantidade excretada, e o ferro do organismo é continuamente reciclado por meio de um eficiente sistema de reutilização das fontes internas de ferro, principalmente, daquele proveniente da hemoglobina $(\mathrm{Hb})$ das hemácias, após hemólise intra e extravascular. ${ }^{1}$ 
O impacto da doação de sangue no status de ferro do organismo tem sido estudado desde a década de $1970 .^{2,3}$ Desde então, sabe-se que a doação de sangue resulta em uma perda substancial de ferro (em média 200 a $250 \mathrm{mg}$ ) em cada procedimento de flebotomia realizado (425 a $475 \mathrm{~mL}$ de sangue), o que pode ter conseqüências variáveis nas reservas de ferro e na saúde dos doadores. ${ }^{2}$ Após a perda sofrida com a doação, ocorre a mobilização subseqüente do ferro das reservas do organismo. Se o doador possuir estoques de ferro normais, apesar da perda ocorrida com a doação, haverá um aumento da mobilização de ferro de seus estoques corporais. ${ }^{4}$ Contudo, essa demanda por ferro aumentará com doações repetidas, podendo levar à maior freqüência de sua deficiência, de modo que a depleção de ferro torna-se uma conseqüência inevitável da doação de sangue. ${ }^{4}$ No caso dos doadores de sangue com alta freqüência de repetição, ou seja, aqueles que doam sangue, sistematicamente, a cada três meses, os estoques de ferro encontram-se sempre sob pressão e as doações múltiplas podem apresentar um efeito deletério no balanço de ferro desses doadores, causando sideropenia. ${ }^{2,3}$

Uma vez que a anemia é a última fase da depleção de ferro, ${ }^{2}$ a triagem para anemia em doadores de sangue, a partir apenas da avaliação da $\mathrm{Hb}$ e/ou do hematócrito, como rotineiramente realizado, na maioria dos bancos de sangue, pode não ser capaz de detectar e excluir doadores com depleção dos estoques de ferro e sem anemia evidente. ${ }^{3,4}$

A literatura estabelece que o nível de ferritina sérica (FS) é um indicador fidedigno das reservas de ferro do organismo, por apresentar forte correlação com o ferro em depósito nos tecidos. ${ }^{2}$ Sugere, ainda, que os níveis de FS podem mobilizar-se e fornecer medidas de confiança para determinar a deficiência do ferro em um estágio adiantado. ${ }^{4}$ A FS é, portanto, diretamente proporcional às reservas de ferro do corpo e a concentração $<12 \mathrm{ng} / \mathrm{mL}$ reflete um estágio de depleção das reservas de ferro do organismo, ${ }^{2-4}$ muito embora esse limite não seja consensual e sejam sugerido, por vezes, valores menores que $10 \mathrm{ng} / \mathrm{mL}$ (ou g/L) como referência da depleção de ferro. ${ }^{2}$ Cada g/L de FS representa cerca de $8 \mathrm{mg}$ a $10 \mathrm{mg}$ de ferro armazenado. ${ }^{2}$ Indiscutivelmente, valores reduzidos na concentração de FS são um forte indicador de depleção de ferro. Por outro lado, valores elevados podem ser observados na presença de infecções, de neoplasias, de doenças hepáticas, de leucemias, na ingestão excessiva de álcool e no hipertireoidismo. ${ }^{2}$

Estudos realizados com doadores de sangue em diferentes cidades, a partir da análise dos índices de FS, demonstraram, claramente, que doadores de sangue desenvolvem sideropenia sem anemia, após doações consecutivas, sendo que essa deficiência parece ser mais dependente da freqüência das doações do que do número acumulado de doações. ${ }^{4,5}$ Entretanto, com o aumento do número das doações, nota-se uma maior queda na taxa de FS, havendo uma forte correlação desta com o número das doações consecutivas. ${ }^{5}$ Além disso, encontra-se bem estabelecido que a sideropenia é muito mais freqüente em doadores de sangue do que em não-doadores. $^{4}$
No Brasil, em estudo realizado no serviço de Hemoterapia do Hospital Israelita Albert Einstein (São Paulo), os autores encontraram uma baixa taxa de sideropenia (2\%) nos doadores e justificaram essa baixa prevalência em função da classe socioeconômica diferenciada que constitui o plantel de doadores da entidade, quando comparada a de outros hemocentros. No entanto, em 300 doadores do Hemocentro da Santa Casa de São Paulo, foi encontrada deficiência de ferro em $11 \%$ dos doadores, atingindo 5,5\% dos homens e $31,7 \%$ das mulheres. A freqüência da deficiência de ferro foi mais alta em doadores de repetição, com mais de três doações regulares ao ano. ${ }^{3}$ Por sua vez, estudo similar conduzido com doadores de repetição do Hemocentro do Amazonas (Hemoam) em que foi dosada a FS, foi demonstrado que, a partir da $5^{a}$ doação consecutiva, esses doadores apresentavam risco de depleção das reservas de ferro, sendo, portanto, fundamental discutir um protocolo de reposição de ferro que evitasse a ocorrência de danos à saúde dos mesmos e a perda da qualidade do sangue doado. ${ }^{4}$

Embora a qualidade e a segurança de uma transfusão sangüínea sejam preocupações constantes dos serviços de Hemoterapia e a triagem clínica, realizada para a doação de sangue, vise, entre outros objetivos, a proteção do doador dos agravos que possam comprometer sua saúde, torna-se fundamental que sejam tomadas medidas efetivas para avaliar a possível depleção dos estoques de ferro causada pelas doações repetidas. A avaliação risco/benefício de se implantar exames que possam analisar as reservas de ferro do organismo, como a dosagem de FS, pelo menos dos doadores com mais de três doações/ano, pode ser fundamental para que se possa assegurar o bem-estar dos doadores e receptores e tornar, dessa forma, a doação de sangue cada vez mais segura.

\section{Abstract}

Iron is a vital element in the human metabolism. It plays a central role in erythropoiesis and is also involved in many other intracellular processes in all the tissues of the body. Blood donation results in a substantial (200 to $250 \mathrm{ng}$ ) loss of iron at each donation (425 to 475 $\mathrm{ml}$ ) with subsequent mobilization of iron from body deposits. Repetitive donations of blood my cause the depletion of iron reserves in blood donors and thus cause health disorders. Recent reports have shown that iron reserves are generally small and iron depletion is more common in blood donors than in non-donors. The high frequency of iron deficiency in blood donors reported by these studies suggests a need for more accurate studies, as measurement of hemoglobin and hematicrit alone is insufficient to identify and exclude prospective blood donors with iron deficiency but without anemia. It is important, therefore, that blood banks evaluate the risk-benefit of implanting tests to analyze organism iron reserves such as the measurement of serum ferritin of all individuals who donate more than three times per year in order to make the blood donation process safer for both donors and transfused patients. Rev bras hematol hemoter. 2008;30(1):62-64.

Key words: Iron reserves; blood donation; serum ferritin. 


\section{Referências Bibliográficas}

1. Cançado RD, Chiattone CS. Anemia de doença crônica. Rev. bras. hematol. hemoter. 2002;24:127-36.

2. Paiva AA, Rondó PHC, Guerra-Shinohara EM. Parâmetros para avaliação do estado nutricional de ferro. Rev Saúde Pública 2000; 34(4):421-6.

3. Cançado RD, Chiattone CS, Alonso FF, Langhi Júnior DM, Alves RCS. Iron deficiency in blood donors. Rev Paul Med 2001;119 (4):132-4.

4. Passos LNM, Yurtserver MSV, Silva UG, Cordeiro GWO, Machado LF, Vasques F et al. Sideropenia sem anemia em doadores de sangue do Hemocentro do Amazonas - Hemoam. Rev. bras. hematol. hemoter. 2005;27(1):48-52.

5. Agha F, Khan R. Ferritin levels in professional blood donors. JAMA 1989;39:124-6.

Avaliação: Editor e dois revisores externos

Conflito de interesse: não declarado

Recebido: 14/12/2006

Aceito após modificações: 01/10/2007

Correspondência: Rita de Cassia Mousinho Ribeiro

Laboratório de Hematologia e Biologia Molecular, Instituto de Ciências Biológicas, UFPa, Campus do Guamá

Rua Augusto Correa $n^{\circ} 01$

66075-900 - Belém-PA - Brasil

Tel.: (91) 3246-9954; (91) 32017571

E-mail:rcmrib@hotmail.com; rcmr@ufpa.br 